\title{
A difusão das organizações de cooperação em defesa no mundo
}

\section{Vinícius Modolo Teixeira}

\section{Introdução}

As Organizações de Cooperação em Defesa (OCD's) têm se estabelecido como forma de alinhamento geopolítico no mundo atual. Essas Organizações, formalizadas através de tratados, pactos, acordos ou mesmo inseridas como agências no interior blocos econômicos, tem cada vez mais se tornado relevantes para compreender as questões geopolíticas que envolvem o mundo, bem como, podem ser a chave para compreender os futuros conflitos que irão se desenvolver no mundo.

Algumas dessas organizações, criadas com o objetivo específico de integrar países através de acordos de cooperação militar, têm obtido relativo sucesso na elaboração de políticas de defesa coletiva, construção e padronização de equipamentos militares e, mais importante, na condução de operações militares conjuntas. Outras organizações, que se encontram em fase inicial de estruturação, têm buscado de maneira clara fomentar os aparatos de defesa de seus membros, bem como, procuram sua modernização frente às novas ameaças que se estabeleceram no mundo pós-Guerra Fria, como terrorismo, radicalismo e separatismo.
Essas organizações, no entanto, tendem a orientar as novas rivalidades e disputas entre as grandes potências mundiais e, também, entre as emergentes. Nesse sentido, a espacialização dessas organizações ao redor do globo pode indicar certas tendências de enfrentamento a médio e longo prazo. Algumas das mais recentes ações militares são sintomáticas de uma nova polarização do espaço mundial, no qual as Organizações de Cooperação em Defesa deverão ter papel fundamental, trazendo o mundo para um novo ambiente de disputas e rivalidades, reforçando a importância dos aparatos militares nojogo geopolítico mundial, contrariando algumas tendências expostas há duas décadas.

A cooperação entre as nações tem sido alvo do interesse das Relações Internacionais, estando associada principalmente ao fenômeno da globalização, ao qual podemos relacionar as teses sobre a diminuição da importância do Estado, das questões militares frente as econômicas e ao processo de desterritorialização das relações. No entanto, alguns autores ligados à teoria neoliberal reconhecem que os conflitos e, consequentemente, as questões militares, ainda serão importantes para o futuro, mesmo com a crescente interdependência entre os países. "Devemos,

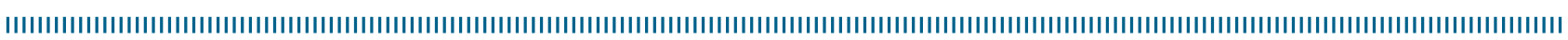
Como citar este artigo:

TEIXEIRA, Vinícius Modolo. “A difusão das Organizações de Cooperação em Defesa no Mundo". In: RÜCKERT, A. A.; SILVA, A. C. P. da; SILVA, G. de V. (Orgs.). Geografia Política, Geopolítica e Gestão do Território: integração sul-americana e regiões periféricas. Porto Alegre: Editora Letra1, 2018, p. 114-130 DOI 10.21507/9788563800367-07 
portanto, ser cautelosos sobre a perspectiva de que o aumento da interdependência é a criação de um admirável mundo novo da cooperação para substituir o mundo mau de conflito internacional". (KEOHANE; NYE, 2012, p. 9).

Dessa forma, o mundo atual ainda está distante de alcançar a paz perpétua ${ }^{1}$ ou mesmo colocar de lado antigos problemas, devendo-se observar disputas entre Estados nacionais, fronteiras e territórios com valores estratégicos. Dessa forma, cabe à Geografia se aliar às Relações Internacionais e Ciências Políticas, na busca para contribuir com análises para a discussão da Geopolítica mundial. Assim, este trabalho busca reunir condições para analisar a construção de organismos cooperativos em questões de defesa, sem estar vinculado à somente um campo de análise ou à uma área da ciência, provendo uma visão mais ampla e diversa sobre essa temática. De modo a particularizar as questões envolvidas nesse trabalho, as iniciativas, tratados e acordos que tenham por base a cooperação em defesa ou militar, serão tratadas como Organizações de Cooperação em Defesa (OCD`s), estabelecendo assim um aspecto geral sobre o tema, ao mesmo tempo em que reconhecemos as particularidades de cada uma dessas organizações.

\section{Defesa, Organizações de Cooperação e a Regionalização do Espaço Mundial}

$\mathrm{Na}$ busca por definir o escopo dessas organizações, devemos nos atentar também para o conceito de Defesa. Nesse sentido, os trabalhos que se debruçam sobre as questões de Defesa, por vezes, trazem associado o conceito de segurança, motivados por razões distintas, muitas vezes condicionadas à escala sobre a qual está inserido o tema estudado ou, então, pela condição proporcionada pela Defesa. Alguns trabalhos utilizam o conceito de segurança em um espectro bastante amplo, dado os variados usos que esse termo pode possuir, inserindo-o em questões diversas, mas que, geralmente,

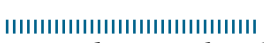

1 Em alusão à obra de Kant, "À Paz Perpétua". podemos apontar como atrelados a problemáticas internas dos países. No entanto, o conceito de segurança pode gerar certa confusão com o de Defesa, os quais não devem ser interpretados como sinônimos.

De acordo com Proença Jr. e Diniz (1998), o termo defesa é atribuído ao conjunto das ações militares que visam garantir o estado de segurança. Dessa maneira, podemos compreender que a segurança de um país, no que diz respeito a sua relação com outros, passa a derivar, ao menos em parte, da defesa. O conceito de defesa, portanto, relaciona-se com os processos que visam garantir a segurança de um Estado, com o emprego das forças armadas e elementos de dissuasão contra outros países. Nesse sentido, buscamos nesse trabalho deixar de lado elementos que tratem da "segurança pública", por compreendê-la como um fator relativo à estrutura e organização interna do Estado, a qual não é atributo, a primeira vista, da defesa. Ainda que se faça o uso das forças armadas para garantia da lei e da ordem, seu papel principal é o da defesa contra ameaças externas, dissuasão e contenção de agressões por parte de outros Estados, e não o combate e a operações em seu interior.

Para os estudos oriundos da geopolítica, ao tratarmos de questões nacionais, regionais e de dinâmicas que operam em uma escala global, na perspectiva de competição entre os Estados, entendemos que a o termo que melhor se adequa à essas análises está fundamentado no conceito de "Defesa", já que, o "setor de defesa pressupõe unidades políticas em disputa, uso das Forças Armadas, risco de guerra e ameaças de natureza geralmente externa, estatal e militar" (MEDEIROS FILHO, 2008, p. 3). Por fim, algumas Organizações de Cooperação em Defesa têm em seu nome ou dentre seus interesses veiculados o uso do termo "segurança". No entanto, a opção por esse termo, nesse caso, deve-se a um artifício para minimizar as críticas quantos aos reais propósitos do bloco, já que, atividades militares tendem a ser malvistas e gerar maior repercussão diplomática em comparação com atividades classificadas como de segurança. No entanto, a busca por segurança nessas organizações se dá através de instrumentos 
oriundos do aparato de defesa de seus membros, com o uso de equipamentos e forças militares. Esse eufemismo, portanto, não pode ser um fator de confusão quanto aos interesses geopolíticos que recaem sobre essas organizações.

A cooperação nesse campo seria caracterizada pela busca de dois ou mais Estados em associar seus respectivos setores de defesa. Para o General Luiz Eduardo Rocha Paiva, a Cooperação em Defesa poderia ser caracterizada quando há a "ajuda, apoio, parcerias e intercâmbios; reuniões e órgãos de defesa; exercícios e missões combinadas; parcerias em outros campos da ciência e tecnologia, desenvolvimento e indústria de defesa" (PAIVA, 2011, p. 38), com o objetivo de gerar confiança recíproca entre os membros dessa cooperação, o que também promove o aumento da segurança entre eles.

Para alcançar certos elementos no processo de cooperação, o Estado aceita abrir mão de uma parcela de informações que lhe são bastante caras, como também, passa a direcionar esforços e recursos para a colaboração com seus parceiros. Dessa maneira, cooperar com outros Estados na área de defesa deve pressupor a confiança entre os aliados, para que o intercâmbio de informações ocorra e os aproxime dos objetivos planejados. Por esses motivos, devemos atentar para a importância dos acordos de cooperação em defesa, já que, o Estado nacional passa a lidar com o partilhamento de elementos chave de sua soberania.

Como em outros processos em que se pressupõe cooperação, essa interação se torna uma tarefa árdua quando há pouca cedência de um dos lados e, a imposição de necessidades que podem ser vistas como interesse particular, de outro. Dessa maneira, a cooperação pressupõe certas condições que muitas vezes são idealizadas e, na prática, tornam-se impeditivos para o avanço de um projeto conjunto. "Estados podem cooperar, apesar de a cooperação ser às vezes difícil de ser atingida e sempre difícil de ser sustentada" (MEARSHEIMER, 2001, p.28). Na visão de John Mearsheimer, a cooperação pode ocorrer, porém, as formas como os ganhos desse empreendimento serão repartidos influenciarão nos seus rumos.

Quaisquer dois estados que contemplem a cooperação devem considerar como os lucros ou ganhos serão distribuídos entre eles. Eles podem pensar na divisão em termos de ganhos absolutos ou relativos [...]. [...] A cooperação é mais difícil de conseguir, no entanto, quando os estados estão sintonizados com ganhos relativos, em vez de ganhos absolutos. Isso porque os estados preocupados com ganhos absolutos têm de garantir que se a torta estiver se expandindo, eles estão recebendo pelo menos uma parte do aumento, enquanto que os estados que se preocupam com ganhos relativos devem prestar muita atenção ao modo como o bolo é dividido, o que complica os esforços cooperativos. (MEARSHEIMER, 2001, p. 28, tradução nossa).

Para este trabalho, devemos considerar uma Organização de Cooperação em Defesa como uma aliança formalizada através de acordos ou tratados, que mantenham em seus documentos de criação, ações como as mencionadas acima, seja como objetivo principal dessa entidade ou como intenção de seus conselhos, secretarias ou agências. Dentro dessa perspectiva, buscamos analisar o estudo sobre as Organizações de Cooperação em Defesa a partir da perspectiva de regionalização do espaço mundial, caracterizado nas últimas décadas pela conformação de blocos e associações entre países em busca de melhor posicionamento no cenário internacional.

O conceito de região tem se apresentado para a Geografia como uma de suas principais ferramentas para as análises espaciais, buscando caracterizar fenômenos semelhantes sobre o espaço, servindo como um de seus conceitos norteadores. Sua utilização como um instrumento analítico contribui para a apreciação de problemas comuns que podem ser espacializados. Para Gomes, as divisões do espaço oriundas da regionalização "não são definitivas, nem pretendem inscrever a totalidade da diversidade espacial, elas devem simplesmente contribuir para um certo entendimento de um problema, colaborar em uma dada explicação" (GOMES,2012,p.63). O processo de regionalização, dessa forma, é caracterizado pela diferenciação do espaço terrestre a partir de 
características comuns. No caso deste trabalho, a regionalização que se destaca é caracterizada pela formação de Organizações de Cooperação em Defesa.

A região e a regionalização do espaço também são conceitos e instrumentos de análise das Ciências Políticas e Relações Internacionais. Barry Buzan e Ole Wæver, exploram a "região" como uma possibilidade de análise através da formulação da teoria dos Complexos Regionais de Segurança (CRS). Como comentam Fucille e Rezende (2013), a divulgação dessa teoria causou grande impacto para as discussões de temas voltados à segurança e defesa, justamente pela inserção do nível regional nessas abordagens. Rezende (2015) comenta que essa teoria busca entender as questões de segurança internacional a partir de um enfoque regionalista, já que para os autores, os problemas de segurança estão mais intrinsecamente associados à sua região, apesar de continuar sofrendo a interferência da polaridade do sistema internacional.

A região, dessa maneira, passa a ser o caminho pelo qual transitam as principais questões de ordem entre os Estados, já que "O nível regional é onde os extremos da segurança nacional e global interagem, e onde a maioria das ações ocorre". (BUZAN; WÆVER, 2003, p.43, tradução nossa). Ainda, segundo os autores, a análise originária do nível regional detém vantagens sobre as abordagens de outros níveis, "Nosso ponto de vista é que a principal vantagem da abordagem regionalista é adquirida com a diferenciação global de dinâmicas regionais de segurança, e as dinâmicas regionais de segurança uns dos outros". (BUZAN; WÆVER, 2003, p. 480, tradução nossa).

A perspectiva regionalista nos serve também como chave para compreender a formação de conflitos e cooperação, fora de uma ótica militarista, sem aderir, contudo, a teses que diminuem o papel do Estado e sua condição de ator no cenário internacional. A teoria regionalista passa a ser complementar às teorias neorrealistas e as ditas "globalistas", já que, assim como a primeira, ela é voltada para questões territoriais, enquanto que temas oriundos da segunda, fornecem alguns dos aspectos presentes nos processos de regionalização, como a formação de blocos econômicos. (BUZAN; WAVER, 2003).

Compreendemos que a conformação das Organizações de Cooperação em Defesa tem estreita relação com os Complexos Regionais de Segurança nos quais se situam. Isso se deve ao fato de os países situados em um mesmo complexo buscarem reduzir o papel negativo das atividades militares entre si, passando a orientar seus aparatos de defesa para fora dos CRS, explorando a vantagem adquirida pela formação de um bloco contra possíveis rivais. Nesse sentido, concordamos com Keohane e Nye, quando fazem considerações sobre o papel de questões militares no interior de blocos, através do que eles propõem como interdependência complexa:

A força militar não é utilizada pelos governos em relação a outros governos dentro das regiões, ou sobre seus problemas, quando a interdependência complexa prevalece. Pode, no entanto, ser importante nas relações de governos com governos fora dessa região, ou sobre outras questões. A força militar poderia, por exemplo, ser irrelevante para a resolução de discordâncias sobre questões econômicas entre os membros de uma aliança, mas, ao mesmo tempo, pode ser muito importante para as relações políticas e militares dessa aliança com um bloco rival. (KEOHANE; NYE, 2012, p. 21, tradução nossa).

Assim como os blocos econômicos tornaramse relevantes para a dinâmica comercial do planeta a partir da segunda metade do século $\mathrm{XX}$, compreendemos que as Organizações de Cooperação em Defesa tiveram e, continuam tendo, papel fundamental para a organização do sistema internacional e orientação de seus conflitos. Passada a primeira década do século XXI, o retorno da rivalidade entre Rússia e EUA, as antigas potências da Guerra Fria, somado ao crescimento das ambições territoriais chinesas, estão diretamente associados ao fortalecimento de seus respectivos aparatos militares, razão pela qual esses países têm buscado na criação a e a manutenção de organizações de cooperação com seus vizinhos e principais aliados. 


\section{A Formação das Organizações de Cooperação em Defesa no Pós-Segunda Guerra Mundial: um recorte histórico}

A cooperação e a formação de alianças entre Estados nacionais não são fatos recentes, tanto para a geopolítica, quanto para as relações internacionais, sendo uma maneira usual encontrada pelos mesmos para alcançar seus objetivos militares. Esse tipo de política, muitas vezes, torna-se um fator determinante para as vitórias e derrotas em guerras, bem como, para evitar a sua deflagração, dissuadindo a ação de potenciais inimigos.

Os Impérios e os Estados nacionais que se organizaram no continente europeu nos últimos séculos, passaram a estabelecer alianças com seus vizinhos visando ampliar sua própria segurança, com ações de bloqueio a territórios, enfrentamento e ataques contra inimigos comuns. Essa política de alianças e os conflitos que se desenvolveram nesse continente estiveram relacionadas à longa e intensa disputa pela supremacia sobre o emergente comércio mundial, o qual tinha na Europa seu centro. A rápida sucessão dos países dominantes devido à intensidade das disputas, promovia também mudanças nos alinhamentos e polarizações do continente.

Nos últimos 500 anos, a política mundial tem sido dominada por estados localizados nas margens do Atlântico Norte. À medida que esses Estados competiam entre si pelo tesouro e pelo poder, eles efetivamente estabeleceram a supremacia imperial mundial da região do Atlântico Norte. Mas essa supremacia não era estável. Foi periodicamente subvertida por rivalidades violentas entre os próprios Estados do Atlântico Norte. Em combinações mutáveis, Portugal, Espanha, França, Holanda e Reino Unido competiram, lutaram e substituíram-se mutuamente como o poder imperial ultramarino preeminente. (BRZEZINSKI, 2009, p. 3, tradução nossa).

Raramente as disputas entre as emergentes potências europeias se desenvolveram sem a conformação de alianças. Seus exemplos podem ser encontrados nos acordos firmados por Inglaterra e Prússia para combater França, Áustria e Rússia, durante a Guerra dos Sete Anos (1756-1763); na coalizão anti-francesa formada por Áustria, Prússia, Rússia e Inglaterra, durante as Guerras Napoleônicas (1803-1815); ou na aliança entre Inglaterra, França e Áustria para combater o expansionismo russo na Guerra da Criméia (18531856).

A partir desses poucos exemplos, nota-se que as alianças eram instáveis e não perduravam a longo prazo, já que as disputas daquele momento implicavam na possibilidade de seu aliado atual tornar-se um inimigo no futuro. Essas alianças, como aponta Thies (2009), tinham pouca coesão entre os aliados e praticamente nenhuma cooperação. As garantias necessárias para enfrentar períodos de crise entre seus membros eram restritas, assim como para a continuidade das alianças após uma vitória conjunta. Muitas vezes, as alianças eram abandonadas com acordos de paz em separado ou em favor de novos arranjos ou parceiros e, dificilmente, mantinham-se por mais do que algumas décadas. Um Estado que conseguisse seus objetivos territoriais ou a subjugação de um inimigo, através do empenho de uma aliança formada para tal fim, teria interesse em abandonar seus aliados o mais rápido possível para não ajudar no fortalecimento de um potencial rival no futuro. O que fica evidente, é que a conformação desse modelo de alianças, tinha como principal objetivo a busca pelo balanceamento de poder no continente, visando neutralizar a ascensão de um Estado que pudesse sobrepujar os demais.

Ainda segundo Thies (2009), é no momento pós-Segunda Guerra que as alianças militares se tornam distintas dos antigos alinhamentos, deixando de ter caráter temporário e passando a ter caráter de organização, com a formalização de compromissos duradouros. Essas alianças, caracterizavam-se pela inserção de mecanismos que visavam a cooperação entre seus membros, com o fornecimento da ajuda, apoio, integração das forças armadas e treinamento conjunto, realizando essas ações de maneira contínua e não só em momentos de conflito, o que as tornavam, também, mais complexas que as antigas alianças 
militares. Dessa maneira, entendemos que a partir desse momento, as alianças passam efetivamente a figurar como Organizações de Cooperação em Defesa, estruturando-se de maneira semelhante aos acordos de cooperação econômica, que passam a orientar o mercado mundial com a formação de blocos regionais.

O impulso para o surgimento desse novo modelo de aliança militar se seu através da crescente tensão Leste-Oeste que passou a orientar a geopolítica mundial a partir de 1945 . A formatação do mundo através das esferas de influência das duas superpotências, foi fator fundamental para a criação de organizações que tinham fins específicos no desenvolvimento de políticas de defesa conjunta. Esses mecanismos, no entanto, eram diretamente associados a um dos lados da disputa, tornando-se tributários das superpotências e de suas estratégias geopolíticas.

Os EUA, dessa maneira, buscaram desenvolver alianças com países que consideravam chave para o combate do comunismo, através das quais passaram a oferecer ajuda, equipamentos e treinamento militar para execução de tal tarefa. A posição estadunidense durante o período da Guerra Fria, de maneira geral, seguiu a ideia formulada por George Kennan, conhecida como "estratégia da contenção", mais tarde delineada de forma oficial através do documento NSC68 , que orientava o combate ao expansionismo soviético através do cercamento de seu território e a manutenção de seus limites no interior do continente eurasiano (GADDIS, 2005), focando em uma área que pode ser compreendida como a que Nicholas Spykman (2008) chamou de Rimland. Essa área estaria localizada entre a URSS e os oceanos que circundam a massa terrestre da eurásia, transformando os territórios dessa região em um cinturão que teria por missão bloquear o avanço soviético e impedir seu acesso aos oceanos que banham o continente. Pela visão de Spykman, a Rimland seria dividida em três porções, a costa da Europa ocidental; o Oriente médio; e a Ásia de Monções. É através da perseguição dessa estratégia que vislumbramos a motivação para a criação das principais Organizações de Cooperação em Defesa lideradas pelos EUA durante a Guerra Fria.
A primeira, mais importante e conhecida, é a Organização do Tratado do Atlântico Norte (OTAN). Essa organização criada oficialmente em 4 de Abril de 1949, contava inicialmente com 12 países membros e foi fortemente influenciada pelo endurecimento do relacionamento com a União Soviética. Sua criação foi precedida pelo Tratado de Bruxelas, que contava somente com membros da Europa ocidental. Dada a importância da questão e a supremacia militar dos EUA, as negociações para a formação de uma aliança militar transatlântica avançaram, suplantando a nascente aliança europeia. Contando com fundamentos de defesa coletiva e ambicionando uma integração entre os aparatos militares de seus membros, a OTAN, sem sombra de dúvidas, foi revolucionária na transformação das relações político militares dos EUA com os países Europeus e também serviu como exemplo para as futuras OCD's.

A cooperação entre os membros da Organização do Tratado do Atlântico Norte (OTAN) na aquisição de armas de tecnologia avançada é um grande exemplo de processos de políticas nacionais interdependentes. Tanto os legisladores europeus como norte-americanos instaram a uma cooperação multinacional cada vez maior. Em parte, essas urgências têm origens econômicas. Dado o aumento dos custos das armas de tecnologia avançada, o desenvolvimento nacional de uma vasta gama de armas avançadas já não é economicamente viável para muitas das nações europeias e até colocou fortes pressões fiscais sobre os mais ricos membros da Aliança, os Estados Unidos. As declarações de política que exortam a uma maior cooperação também têm justificativas militares: uma maior cooperação poderia avançar a padronização de armas - ou seja, a aquisição multinacional de armas comuns ou pelo menos armas que poderiam operar em conjunto mais eficaz. (BAJUSZ, 1980, p. 264, tradução nossa).

A criação e o propagado sucesso de suas ideias, motivou a continuidade da estratégia de contenção através da formação de outros blocos de cooperação em defesa, que também deveriam contribuir para o enclausuramento da URSS. Esses blocos tiveram vida efêmera, porém, contribuíram para as estratégias de defesa de diversos países, influenciando nas relações dos EUA com a região em que se encontravam. Dessa maneira, outras duas organizações com princípios semelhantes 
à OTAN, foram criadas no Oriente Médio e no Sudeste Asiático, simbolizando a efetiva presença dos EUA sobre a Rimland. Essas organizações deveriam servir como orientadoras dos programas de assistência militar dos EUA para seus aliados, modernizando suas forças armadas ao mesmo tempo que os tornavam clientes da indústria de defesa da superpotência capitalista.

Como resultado, foram criadas a Organização do Tratado do Sudeste Asiático (SEATO), em 1954 e, a Organização Tratado Central (CENTO) em 1955. Tanto a CENTO, quanto a SEATO, deveriam compor junto à OTAN e às alianças dos EUA com Japão e Coreia do Sul, um anel de isolamento da massa eurasiana, o qual seria completado com a China comunista, após o rompimento de suas relações com a URSS.

Fora da "Rimland", outros blocos foram criados no intuito de assegurar a supremacia estadunidense na Guerra Fria. No pacífico, a organização criada foi chamada de ANZUS, em 1951, sigla derivada da inicial dos países membros, Austrália, Nova Zelândia e Estados Unidos, a qual inseria este último país em uma área próxima à importantes rotas comerciais, como o estreito de Malaca e de países como Indonésia, China e Vietnã. (PUGH, 1989).

Já no continente americano, os EUA estabeleceram uma forte aproximação na área de defesa com Canadá, iniciada logo após a Segunda Guerra Mundial. Essa aliança, iniciada com o Military Cooperation Committee (MCC), de 1946, previa a defesa conjunta da massa territorial dos dois países, que também se tornariam membros da OTAN e, posteriormente, implementariam o sistema de defesa conjunto North American Aerospace Defense Command (NORAD), responsável pela vigilância do espaço aéreo em seus territórios. Esse último mecanismo tornou-se o principal sistema de vigilância aeroespacial no continente, responsável pelo monitoramento de toda a porção norte da região, rota mais provável de bombardeiros e mísseis soviéticos.

Por fim, na América do Sul, a política dos EUA para assegurar seus objetivos estratégicos durante a Guerra Fria, gerou o Tratado Interamericano de Assistência Recíproca (TIAR), em 1947. Esse tratado, assinado antes mesmo da formalização do pacto da OTAN, esteve longe de simbolizar uma organização de defesa como as outras já mencionadas, comportando-se na verdade, como um instrumento de segurança para estratégia dos EUA para a região, permitindo-o intervir na política interna dos países Latino Americanos, com o pretexto de defesa coletiva, sem, no entanto, contribuir efetivamente para melhorias nos aparatos de defesa dos seus aliados. A realidade que se apresentou para os países da região, no que diz respeito ao acesso a equipamentos de defesa e a cooperação com os EUA, ficou muito aquém da esperada pelos parceiros continentais. A política oficial dos EUA, inclusive, foi de negar acesso aos países latino americanos a itens de defesa modernos (MARTINS FILHO, 2005), já que a região estava distante do principal foco de atenção geopolítico da superpotência ocidental.

Por seu lado, a União Soviética firmou o tratado de cooperação chamado Pacto de Varsóvia, em 1955, que congregava, além das repúblicas socialistas soviéticas, os países de sua esfera de influência no leste europeu. No entanto, essa organização falhou em ser o bloco aglutinador dos países socialistas, já que a antiga Iugoslávia e a China comunista não aderiram à essa aliança, expondo divergências na condução de políticas de defesa entre os países de orientação comunista.

Ao contrário do pacto da OTAN que foi fundado em 1949, o Pacto de Varsóvia não era uma organização independente mas funcionava como parte do ministério soviético de defesa. De facto, durante os mais de 30 anos desde que foi estabelecido, tinha servido bem o objetivo estratégico do soviete de controlar seus aliados do leste europeu através de meios políticos e militares. A União Soviética o tempo todo dominou os exércitos desses aliados e tomou decisões para eles, mesmo à custa de seus interesses nacionais. (WU, 2005, p.4205, tradução nossa).

Assim como os EUA, a URSS paralelamente a sua organização passou a realizar tratados bilaterais de cooperação em defesa com países de outros continentes, o que não atingia o status de organização, porém, driblava o cerco 
territorial a que tinha sido imposta na Eurásia. Esses acordos tornaram-se elos frágeis dentro da estratégia de defesa da URSS, estando sujeitos a mudanças políticas em seus aliados, pelos quais posteriormente os EUA viriam a ter acesso a parte da tecnologia bélica usada pelos países socialistas.

O espaço mundial, dessa maneira, foi preenchido por uma série de alianças com fins de proporcionar a defesa coletiva entre as superpotências e seus aliados, moldando o jogo geopolítico do período da Guerra Fria. Através dessa regionalização do espaço, baseada nas afinidades político-militares, desenvolveramse também outras formas de cooperação, como culturais, econômicas e sociais, já que as parcerias estratégicas passaram a influenciar esses processos de circulação. $\mathrm{O}$ mesmo deve ser pensado em relação aos conflitos ocorridos nesse período, os quais contaram com a participação direta de ao menos um membro de uma dessas organizações e, indiretamente, com a influência de outros.

A evolução dessas Organizações de Cooperação em Defesa, de maneira geral, não se fez sem a inocorrência de crises e complicações, derivadas da ausência de confiança entre seus membros e das negociações em torno das formas de cooperação propostas pelas superpotências. Essas dificuldades levaram ao esfacelamento de parte delas, sendo substituídas por acordos bilaterais, menos abrangentes.

Mesmo sendo parte da estratégia de contenção através da "Rimland", as organizações da SEATO e CENTO, desde o princípio, tiveram um papel secundário frente a OTAN. Essas organizações contavam também com problemas distintos dos que eram enfrentados na Europa, com seus membros em diferentes estágios de desenvolvimento econômico e social, colocando em xeque a suas capacidades de contribuir com essas organizações. Os países do Oriente Médio e Sudeste Asiático participantes dessas alianças nem sempre podiam alinhar forças militares para cumprir com seu papel de dissuasão, o que obrigava os EUA a se envolverem mais diretamente nesses países, mesmo para resolverem insurreições locais. (GADDIS, 2005).
Soma-se a isso, a falta de objetivos claros e um inimigo comum capaz de orientar a defesa dessas organizações. "O objetivo do Paquistão em adquirir armamentos dos Estados Unidos não foi para a segurança contra ataque comunista, mas para proteção contra a Índia. Os membros árabes da CENTO se armaram não contra a URSS mas contra Israel”. (KISSINGER, 1969, p.68). Nessas circunstâncias, essas organizações acabaram por se desintegrar ao longo dos anos 1970. O papel dos EUA na região, no entanto, não se esvaneceu, sendo substituído por acordos bilaterais com países como Paquistão, Tailândia, e Arábia Saudita.

Na América do Sul, as dúvidas sobre a validade da aliança firmada com a superpotência do continente começaram a ser questionadas ainda nos anos 1960, continuando ao longo dos anos 1970 , podendo ser simbolizadas pelas constantes negativas recebidas pelos países quanto ao acesso a equipamentos aeronáuticos modernos. (TEIXEIRA, 2016). A questão mais grave que colocaria o TIAR em xeque viria com a eclosão do Conflito das Malvinas, em 1982, quando os EUA forneceram apoio ao Reino Unido, em detrimento da colaboração com a Argentina, em clara afronta aos princípios de defesa contra agressões externas que norteavam o documento dessa organização. (DUARTE, 1986).

A ANZUS foi outra organização que após enfrentar uma séria crise, praticamente teve seu fim decretado. Em 1984, após se negar a receber navios movidos à energia nuclear ou dotados de armas atômicas dos EUA, a Nova Zelândia teve sua participação suspensa nessa aliança no ano de 1986, fator que decretou o fim das relações de segurança entre os dois países (PUGH, 1989). Apesar de formalmente ainda existir, as atividades ligadas à defesa dessa aliança foram substituídas pelos acordos bilaterais de defesa entre os dois países do Pacífico com os EUA.

A OTAN, principal organização de defesa ocidental, também não se viu livre de sobressaltos. Como afirma Thies (2009), pensar sobre esse bloco militar é pensar em suas sucessivas crises. Para esse autor, não houve momentos em que essa aliança não estivesse envolta em crises de 
Mapa 1. Organizaç̃oes de Cooperação em Defesa no Período da Guerra Fria (1945-1991). Org. TEIXEIRA, V. M., 2018.

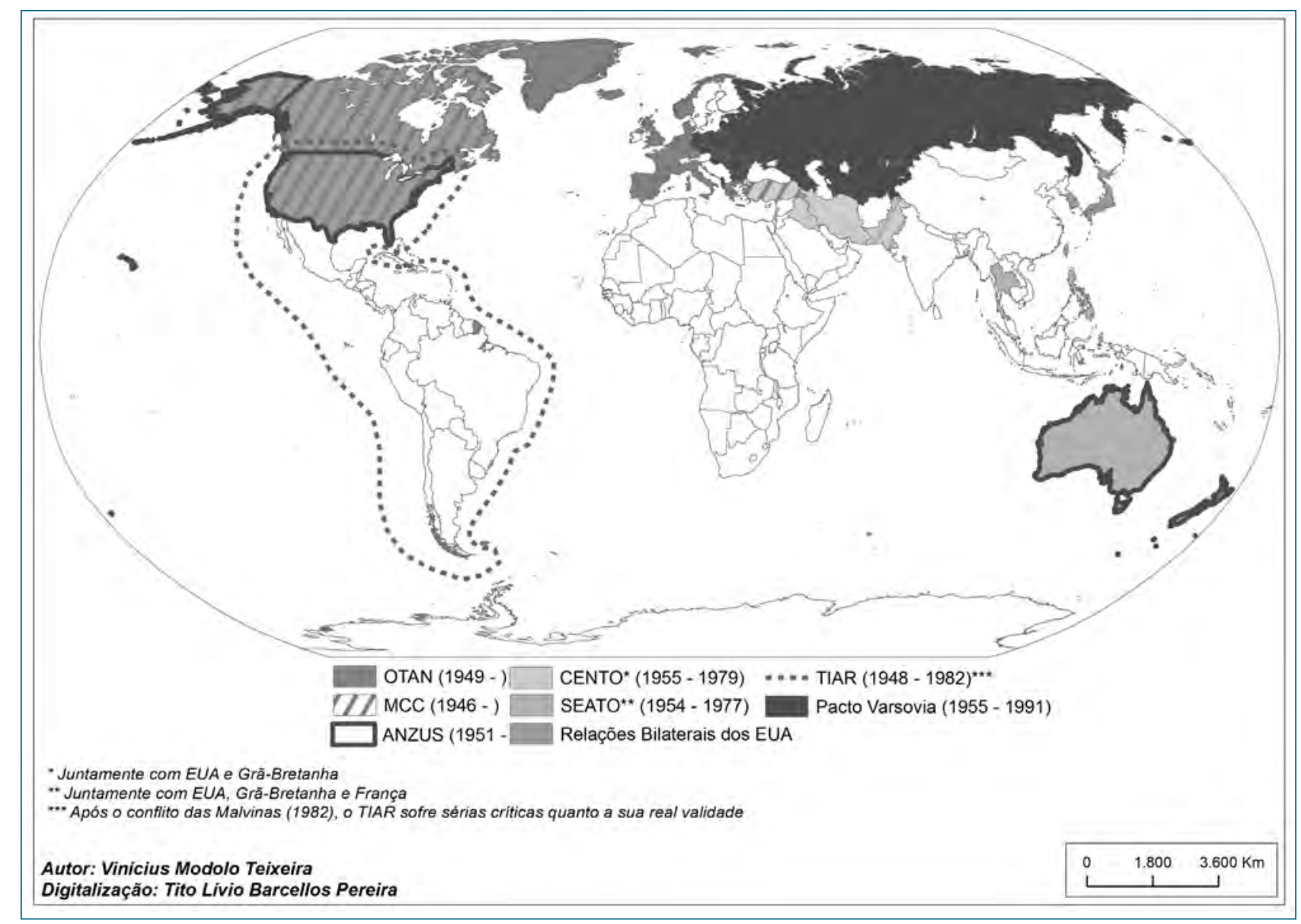

objetivos ou quanto à execução de seus projetos, demonstrando a dificuldade para definir um futuro comum no âmbito de uma Organização de Cooperação em Defesa. Os projetos de construção conjunta de armamentos e padronização de seu aparato bélico, que podem ser apreendidos como símbolos do sucesso dessa aliança, são resultado de duras negociações. No entanto, essa aliança se mostrou resiliente às suas inúmeras crises durante a Guerra Fria e, após o fim da mesma, conseguiu superar o vácuo deixado pelo desaparecimento da União Soviética como justificativa para sua existência, ampliando o número de aliados e sua área de atuação.

\section{As organizações de cooperação em defesa no momento atual}

O período final da confrontação LesteOeste, como visto, tragou junto a si algumas das Organizações de Cooperação em Defesa que tinham sido criadas com base nas estratégias de enfrentamento do período bipolar. A partir de então, as teses dominantes sobre a globalização e a consequente regionalização do espaço mundial no pós-Guerra Fria, pautada em grande parte pelo discurso e lógica econômica neoliberal do "Consenso de Washington", passaram a influenciar as análises sobre a dinâmica mundial, a partir de uma ótica baseada nas condicionantes de livre mercado como principal forma de relacionamento entre as nações. Nesse sentido, a atenção se voltou para a apreciação de blocos regionais orientados para a cooperação econômica, os quais estiveram entre os principais argumentos do processo de globalização do capitalismo, incentivados pelo surgimento de blocos como o MERCOSUL, o NAFTA, a APEC, a União Europeia, dentre outros.

Esse modelo de cooperação moldado por bases econômicas, apesar de seu maior alarde nos anos 1990, não extinguiu a colaboração estratégica desenvolvida através da cooperação em defesa. 
A criação desses blocos econômicos não impediu que organismos com objetivos militares fossem criados e também ampliados, demonstrando que o poder militar continuaria um fator relevante para as relações diplomáticas, a despeito do discurso pacifista e da momentânea diminuição de gastos militares ao final do século XX. Ao contrário do que alguns autores ousaram propagar, os enfrentamentos militares continuaram a ocorrer e a cooperação em defesa continuou como uma das principais formas de cooperação no mundo.

Ao passo que o fim da URSS, em 1991, fez ruir o Pacto de Varsóvia, principal estrutura antagônica da OTAN, essa passou a buscar novos elementos que justificassem seu papel como aliança militar. Nesse sentido, os conflitos ocorridos na região dos Balcãs nos anos 1990, serviram inicialmente como fator aglutinante da aliança, substituídos no novo século pelo combate ao terrorismo internacional. Essas novas ameaças serviram de argumento à essa organização para operar em áreas distantes do Atlântico Norte, através de diversas operações na África, Oriente Médio e Oceano Índico. Não obstante, a OTAN ampliou o conjunto de países participantes de sua aliança, expandido o tratado por praticamente todo o leste europeu, antiga área de influência soviética, anexando ex-membros do Pacto de Varsóvia.

Os EUA, na condição de única superpotência no pós-Guerra Fria, continuou a buscar o enlaçamento com novos aliados através do estabelecimento de acordos de Cooperação em Defesa, firmando relações com países de diversas partes do globo, para isso atribuindo-lhes o título de Aliados ExtraOTAN. Esses acordos bilaterais de cooperação, a despeito de não se constituírem como organização de fato e não apresentarem inimigos comuns e ameaçadores como a antiga URSS, tratam especificamente da cooperação em defesa entre os países signatários e os EUA, dentre quais figuram Israel, Egito, Paquistão, Coréia do Sul, Japão, Marrocos, Jordânia e Tailândia. Dessa maneira, a estratégia política dos EUA continuava a pautar a defesa como principal fator de influência sobre o globo, buscando continuamente estabelecer alianças e pactos ao redor do mundo. Através do estabelecimento desses acordos, os países aliados dos EUA passaram a ter acesso a equipamentos militares restritos, bem como a disponibilidade de financiamento para suas aquisições oriundas de indústrias estadunidenses.

Por outro lado, a ampliação da OTAN a partir do final dos anos 1990 para as proximidades da fronteira russa não passou despercebida a esse país como uma séria ameaça a sua segurança, levando a criação de organismos capazes de contrabalançar a influência da aliança atlântica. (THIES, 2009). Dessa maneira, uma das primeiras reações da Rússia foi tentar reestabelecer as parcerias militares com países que lhes eram mais próximos cultural e militarmente.

O primeiro movimento se deu com a criação do Tratado de Segurança Coletiva, em 1992, também chamado de Pacto de Tashkent, que incluía além da própria Rússia, Armênia, Cazaquistão, Quirquistão, Tadjiquistão e Uzbequistão, aos quais se somariam como membros oficiais em 1994, Bielorrússia, Azerbaijão e Geórgia. A conturbada situação econômica russa nessa década e as questões territoriais envolvendo alguns desses vizinhos que se somaram aos ressentimentos do passado de dominação soviética, levaram a saída de Azerbaijão, Geórgia e Uzbequistão do tratado.

Já sob o governo de Vladimir Putin, esse tratado passou a se chamar Organização do Tratado de Segurança Coletivo (OTSC), a partir de 2002, tornando-se efetivamente uma aliança militar. Seus objetivos estão fortemente associados aos interesses russos na região, aos quais os países membros estão atrelados e de certa maneira dependentes. Dentre as atividades que passaram a se desenvolver sob a organização estão, a formação e treinamento de oficiais dos países signatários em academias militares russas; execução de exercícios militares anuais e; fornecimento de equipamentos de defesa avançados produzidos pela Rússia, com especial interesse em equipamentos relacionados a defesa aeroespacial. Apesar de inicialmente a argumentação sobre os interesses dessa organização estarem relacionados ao combate ao terrorismo no pós-11 de setembro de 2001, o real objetivo dessa organização não estaria voltado 
ao combate a grupos rebeldes e terroristas, e sim, ao fortalecimento do entorno estratégico russo, frente à expansão da OTAN. (FROST, 2009).

Essa organização, no entanto, encontra certas dificuldades em estabelecer seus objetivos comuns de defesa. Dado o enorme território que abarca, a OTSC sofre influência de três complexos regionais de segurança diferentes - o Leste Europeu, o Caucasiano e o Centro Asiático - sobre os quais tem tido dificuldades em realizar contribuições significativas para evitar conflitos. (BAEV, 2014). Isso fica claro quando se observa a situação da Geórgia, que inicialmente fazia parte do Pacto de Tashkent nos anos 1990, e em 2008 entrou em confronto direto com a Rússia devido a disputas por uma região separatista em suas fronteiras.

Em um segundo campo, a Rússia passou a fazer parte de outra organização no ano de 1996, porém, a partir de uma iniciativa chinesa de cooperação. A chamada Organização de Cooperação de Xangai (OCX), ou simplesmente Pacto de Xangai, foi criada de forma a integrar China e Rússia às nações da Ásia central, através do objetivo comum de combater os chamados "três males" que poderiam deflagrar conflitos nessa região: o terrorismo, o extremismo religioso e o separatismo. Ambas potências mantêm interesses em tornar a região da Ásia Central em um ambiente próspero sobre o qual poderiam exercer sua influência, devendo, portanto, contribuir para a estabilização e enlaçamento diplomático com esses países. Assim, os países que foram inicialmente convidados a unir-se a essa organização, eram Estados de onde poderiam partir algumas dessas ameaças, Cazaquistão, Quirguistão e Tajiquistão. Em 2001 a organização foi ampliada, com a adesão do Uzbequistão como membro efetivo e, Mongólia, Irã, Índia e Paquistão, como países observadores.

A criação de uma organização conjunta entre Rússia e China, com elementos claramente voltados à segurança e, subjetivamente à defesa, causou preocupação de analistas ocidentais, que chegaram a rotular a iniciativa como "novo Pacto de Varsóvia".

O objetivo principal da OCX tem sido objeto de grande preocupação e ceticismo entre analistas ocidentais. A maioria optou por retratar a OCX como um dispositivo geopolítico conjunto russo-chinês para combater a crescente presença dos EUA na Ásia Central e como um bloco anti-ocidental em geral. Essas interpretações variam de relatos sensacionalistas proclamando que "a OCX é" a organização mais perigosa de que os americanos nunca ouviram falar "e" um potencial Pacto de Varsóvia" [...]. (ARIS, 2009, p.458, tradução nossa)

Parte da preocupação advém da reaproximação russo-chinesa logo após o fim da URSS, pautada por uma massiva retomada das negociações de material militar, que estavam interrompidas desde os anos 1960. A partir de 1991, segundo consulta aos registros Do Stockholm International Peace Research Institute (SIPRI, 2016), as vendas de armas da Rússia para a China foram feitas em grande quantidade e envolveram sistemas de armas avançados, como equipamentos de defesa antiaérea, sistemas de radar, aviões de caça, transporte e etc. Essas preocupações foram reforçadas com a formalização do Tratado de Amizade entre as duas nações no ano de 2001, que apesar de não significar uma aliança militar, dá indícios sobre a possibilidade de tratativas nesse sentido, caso necessitem. (TURNER, 2009).

Há, no entanto, a possibilidade da ambivalência russa, com a sobreposição da OTSC sobre a OCX vir a se tornar um fator complicador para o futuro de suas relações com a Ásia Central. Apesar de ainda refletir um problema, as futuras pretensões chinesas de acessar essa região podem vir a colocar um peso sobre a existência conjunta dessas organizações para os russos.

Embora a OCX e a OTSC pareçam ter objetivos semelhantes e tenham assinado um acordo de cooperação mútua durante a CIS em 2007, as discrepâncias entre as duas são reveladoras e refletem diferenças entre a estratégia chinesa e a russa no que se refere à multipolaridade e à segurança. Primeiro, o escopo pretendido da OTSC é muito mais amplo do que o da OCX, como exemplificado por suas ambições de imitar a OTAN. Em segundo lugar, a OTSC foi estabelecida como mais uma aliança militar do que a OCX, cuja carta só menciona superficialmente as implicações militares da organização. (TURNER, 2009. p.177, tradução nossa).

Embora para a Rússia, os objetivos atrelados a ambas organizações perpassem pela exclusão 
da influência estadunidense da Ásia Central, isso pode se tornar uma complicação no futuro. Se por um lado a OCX realiza manobras militares que servem para enfraquecer o prestígio militar dos Estados Unido e aumentar o da Rússia, criando uma voz política unida pela retirada estadunidense da Ásia Central, por outro lado, aumenta a influência chinesa nessa região (FROST, 2009). Nesse sentido, a OTSC poderia ser utilizada para bloquear os membros de uma aliança extraOTAN e também, frear os esforços chineses para desenvolver relações militares com os estados da Ásia Central.

Uma questão importante para a OTSC em desempenhar qualquer papel de segurança significativo na Ásia Central é o caráter ambivalente de suas relações com a China, que continua cautelosa em assumir compromissos firmes com a segurança na região, embora tenha todo o motivo para supor que seu interesse não seria protegido por qualquer outro "provedor". Moscou está tentando ter ambos os lados: por um lado, a construção de laços com a China na Organização de Cooperação de Xangai (OCX); E por outro, mantê-la afastada pelo fortalecimento da OTSC. (BAEV, 2014 p. 46, tradução nossa).

Em 2015, Índia e Paquistão iniciaram o processo para tornarem-se membros permanentes da Organização de Cooperação de Xangai, sendo finalmente aceitos em junho de 2017, ampliando a participação de potências nucleares no bloco. A inclusão conjunta desses dois países que possuem uma histórica rivalidade e potencial conflitivo, só pode ser compreendida como uma manobra diplomática de Rússia e China, parceiros estratégicos, cada qual e respectivamente, de Índia e Paquistão, para controlar as possíveis tensões derivadas desses países. A inclusão de apenas um deles poderia gerar desconfortos e atrair o bloco para os problemas que orbitam a relação entre ambos, ao passo que a adesão conjunta poderia minimizá-los.

Em relação aos outros continentes, o desenvolvimento de Organizações de Cooperação em Defesa também passa a ser pleiteado como estrutura importante para o futuro dessas regiões. Tal como a relação norte-sul, exposta na regionalização econômica, a regionalização das
OCD passa por uma divisão semelhante. Apesar de vários países pobres da Eurásia estarem inseridos nas organizações já apresentadas, sua inclusão passa mais pelo interesse das potências líderes desses blocos do que por sua própria iniciativa.

A África, continente que se tornou símbolo de dificuldades econômicas e sociais na última metade do século XX, continua a sofrer com problemas variados. As fragilidades econômicas, os problemas sociais e a imensa diversidade nacional, da qual derivam as rivalidades étnicas e os conflitos, são problemas que ainda não foram completamente superados. A existência de mais de cinquenta países independentes ocupando esse território, é outro obstáculo para o estabelecimento de relações de cooperação sólidas entre eles, já que nem todos contam com governos estáveis e objetivos regionais comuns, criando um ambiente de pouca interdependência. Soma-se a isso o passado colonial recente, do qual ainda alguns países são dependentes diretos na área de defesa de suas antigas metrópoles. Ao analisar a situação do continente sob a ótica dos Complexo Regionais de Segurança no início dos anos 2000, Buzan e Wæver (2003) destacam a dificuldade em abordar o continente a partir de sua teoria. A exceção da porção sul, o continente conta com proto-complexos regionais ou então áreas não-estruturadas, com vários países sequer pertencentes a uma região definida, o que torna o continente um ambiente pouco propício para a criação de organizações regionais.

O que assumimos como visão do momento atual do continente Africano é que seus países continuam a buscar relações diplomáticas e formalização de acordos de defesa com potências externas, capazes de prover suas necessidades em equipamento, treinamento e em alguns casos, a proteção direta. Nesse sentido, como observado no Mapa 02, o espaço vazio deixado por organizações desse tipo no continente passa a ser alvo de alianças com potências extra-regionais, que buscam ampliar sua influência sobre a região.

Os EUA com suas relações bilaterais e de classificação como aliados Extra-OTAN, com alguns países do norte do continente, são os mais 
Mapa 2. Principais Organizações e Acordos de Cooperação em Defesa atuais. Org. TEIXEIRA, V. M., 2018.

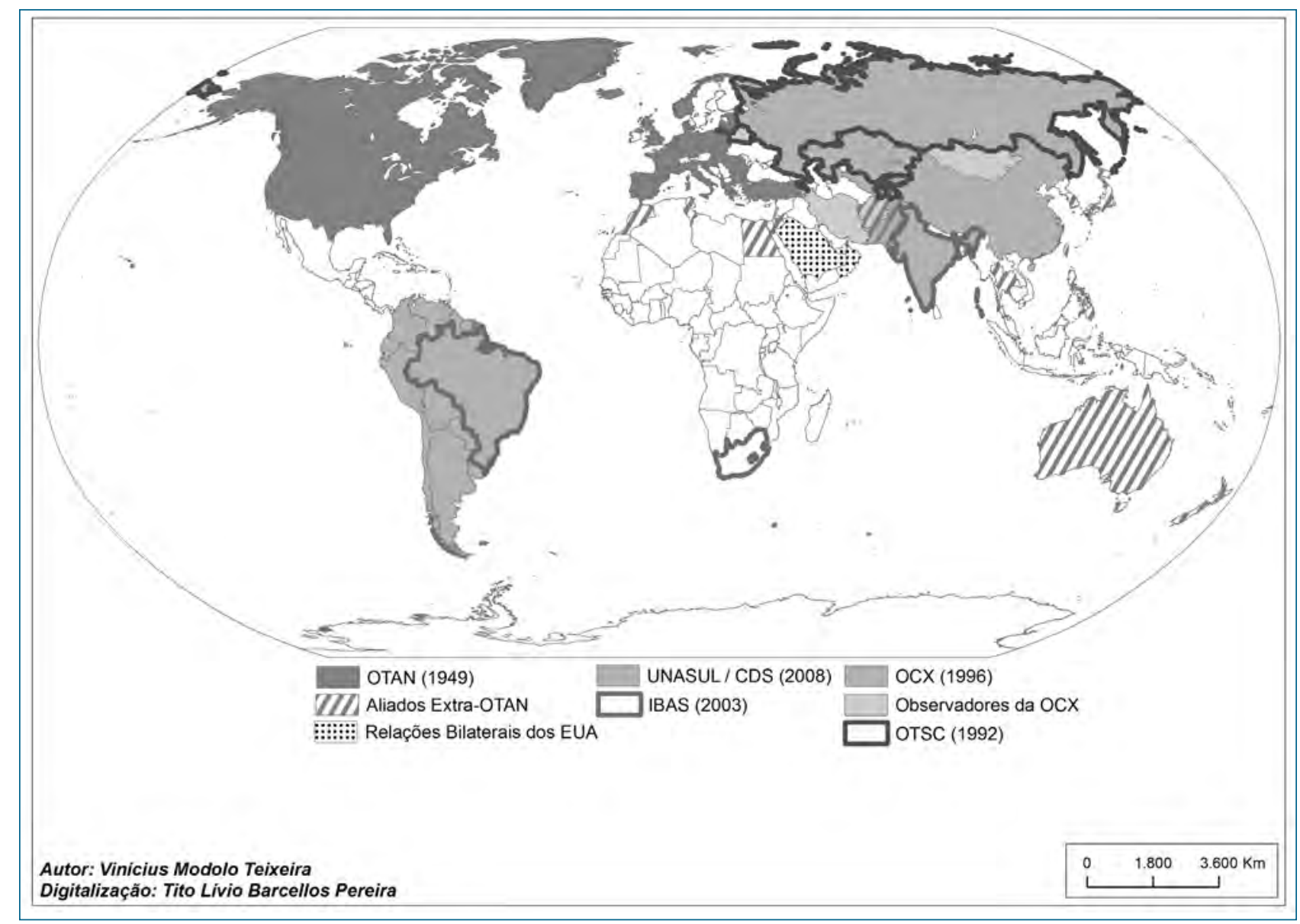

visíveis. Da Europa, a França continua a manter forças militares baseadas em países do centro do continente, assim como o fornecimento de equipamentos a grande parte de suas antigas colônias. A tímida participação brasileira nas relações com a Namíbia e em países de língua portuguesa no início dos anos 2000 não prosperou, restando apenas como símbolo maior dessas relações a iniciativa de cooperação chamada de IBAS (Índia, Brasil e África do Sul), de 2003, que contava com diálogos na área de defesa, porém, cujo futuro permanece incerto. $O$ país que mais tem buscado se inserir em relações de defesa com países africanos é a China. Esse país tem claramente buscado estabelecer relações de confiança nesse campo com alguns países do continente, fornecendo-lhes material militar, treinamento e assessoria em troca de suas commodities. Assim, a pouca estruturação do complexo regional de segurança da África, derivado de sua fragilidade histórica, deixa o continente em meio a disputas externas, nas quais seus países passam a ser cooptados por Organizações e potências externas ao continente.

Já a América do Sul, também se encontra inserida nessa regionalização a partir de acordos voltados para a Defesa conjunta. A assinatura do documento de criação do Conselho de Defesa Sul-Americano (CDS), em 2008, consagrou o que há muito já havia se tentado no continente, um ambiente para a construção da confiança mútua e superação das rivalidades, aproximando os países sul-americanos através de um mecanismo de cooperação em defesa. O Conselho de Defesa Sul-Americano, passada quase uma década de sua criação, conseguiu estabelecer um ambiente seguro para discussões sobre o tema no continente, contando atualmente com uma Escola de Defesa, sediada no Equador, assim como iniciativas de cooperação entre alguns de seus membros. 
Sendo ainda uma organização recente e sujeita às alterações de interesses dos governos locais, levará algum tempo para que políticas mais profundas e uma efetiva cooperação entre seus membros se instale na região. No entanto, tal iniciativa se alinha aos movimentos apresentados nos outros continentes, demonstrando que esses mecanismos de cooperação não passam despercebidos aos olhos de políticos e militares da América do Sul, como uma possibilidade concreta para o desenvolvimento de suas forças militares.

\section{Conflitos regionais e a interferência das OCDs: rumo a um novo-velho enfrentamento?}

Ao tratarmos da Cooperação em Defesa ao redor do mundo, não podemos deixar de mencionar as reações quanto a sua criação e o emprego da força militar que essas organizações reúnem. Nos anos recentes, alguns conflitos têm dado sinais de uma possível disputa entre Organizações, principalmente os ocorridos em territórios lindeiros ao das maiores OCD's. Nesse sentido, observamos que as Guerras ocorridas na Geórgia, Síria e Ucrânia, bem como, as intervenções na Líbia e Iraque, devem ser analisadas a partir de suas posições em relação às Alianças formadas na Eurásia. A posição geográfica em que esses países estão situados coincide justamente sobre as áreas de contato entre a OTAN, OTSC e OCX, havendo clara influência dessas organizações ou das potências que as lideram nos conflitos e intervenções acima citados.

O conflito entre Rússia e Geórgia em 2008 pela região da Ossétia do Sul, apesar de perdurar por poucas semanas, marcou a região pela intensidade e pelo uso de armas de grande valor estratégico pela Rússia, bem como pela violência de alguns combates. As relações entre esse conflito e a expansão do sistema de alianças ficam mais claras quando se estabelecem os laços entre as posições políticas internas da Geórgia e seu apoio pela OTAN. Pouco antes do conflito, o presidente da Geórgia, Mikheil Saakashvili, demonstrou forte interesse do país em se tornar membro da aliança atlântica. Do mesmo modo, políticos ucranianos contrários a continuidade do relacionamento dependente com os russos, viam na OTAN uma possibilidade de tornar o país livre dessa relação secular. Quando do conflito ocorrido pela região da Ossétia do Sul, no ano de 2008, a Ucrânia prestou efetivo apoio ao governo georgiano e suas forças armadas, fornecendo-lhes sistemas de artilharia antiaérea com os quais a Geórgia obteve diversos abates de aeronaves russas. Além disso, segundo Aminov (2008) há indícios de que a OTAN fornecia informações de seu sistema de vigilância aérea situado na Turquia, através de um canal de comunicações exclusivo, que ajudava a monitorar os movimentos das aeronaves russas, sendo essencial para a destruição de algumas delas, além de permitir o conhecimento dos seus potenciais alvos de maneira antecipada, evitando a destruição de instalações vitais da Geórgia.

O conflito na Síria, tal como o da Líbia, derivado das manifestações da Primavera Árabe, acabaram sofrendo grande influência da OTAN na sua evolução. No caso Líbio, o apoio da organização aos grupos rebeldes para a derrubada de Muammar Kadhafi, foi bastante significativo, com centenas de missões de bombardeio partindo do continente europeu em direção ao país Africano. Tal situação tornou a se repetir em alguns pontos da Síria, com missões em apoio a grupos contrários ao presidente Bashar Al Assad. Nesse caso, no entanto, o maciço envolvimento russo no conflito, em auxílio as tropas do governo, impediu uma maior mobilização das forças da OTAN no país, que se limitou a atacar alvos do grupo Estado Islâmico no leste da Síria e em partes do Iraque. No entanto, o atrito entre aeronaves russas e da OTAN, elevaram a tensão na região, demonstrando significativo aumento do potencial de conflito entre os dois lados.

É significativo pensar a posição Síria como extremamente valiosa para a Rússia, da qual o país é aliado, situando-se em meio a países membros da OTAN, aliados dos EUA e países com os quais esse último mantém relações bilaterais próximas. A queda do regime Sírio resultaria 
Mapa 3. Conflitos e potenciais áreas de atritos entre a OTAN, OTSC e OSX. Org. TEIXEIRA, V. M. 2017.

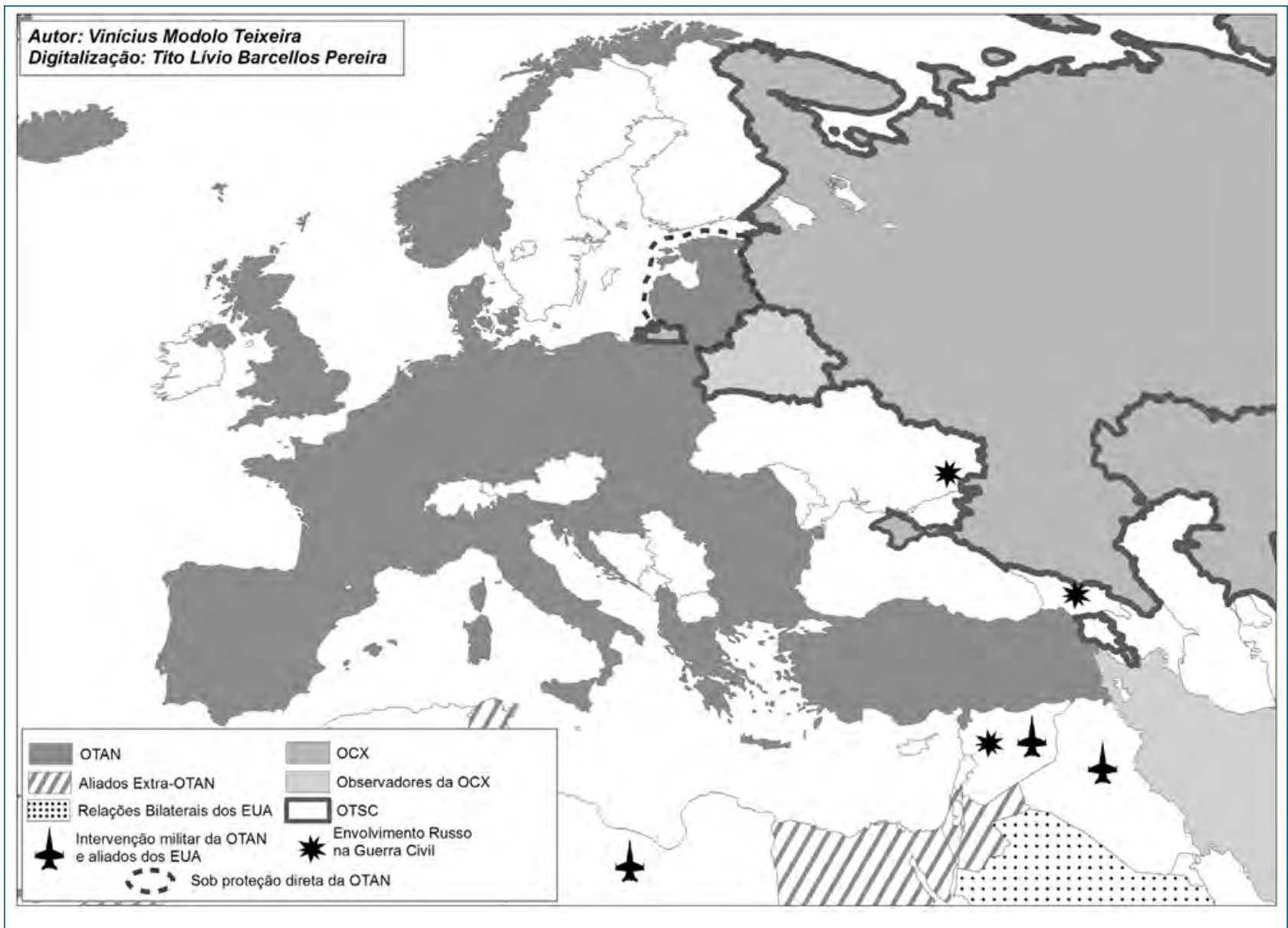

certamente no retrocesso das relações russas com a Síria e isolamento desse país na região do mediterrâneo. Também deve-se mencionar, o apoio chinês ao regime sírio, enviando militares e ajuda humanitária ao país, o que coloca o país criador da OCX em um conflito do lado oposto aos membros da OTAN.

Por fim, a Ucrânia que representa o único espaço livre entre a OTSC e a OTAN no que antes fora a zona de influência imediata da URSS, tornouse um território em disputa. Desde o início dos anos 2000, os governos pró-ocidente da Ucrânia fazem menção de ingressar na aliança atlântica, levando a duras críticas do lado russo, sendo que a possível anexação desse país pela OTAN tornou-se uma das razões da tensão enfrentada a partir de 2014. No conflito desencadeado nesse ano, ficou inegável a influência da OTAN na evolução da crise, o que gerou a tentativa de separação do Leste russófono do país e a retomada da península da
Crimeia pela Rússia. Pelo lado russo, o apoio aos movimentos separatistas através de sua fronteira e a participação de tropas especiais nos combates também foi reportado, demonstrando o interesse do país em preservar sua área de influência nos territórios fronteiriços. (MONIZ BANDEIRA, 2016).

Geórgia, Síria e Ucrânia são países com os quais a influência russa esteve ativa nos últimos vinte anos e que representam importantes ativos territoriais, culturais, econômicos e geopolíticos para esse país. A mudança de posição, com a filiação à OTAN ou a queda de governos com os quais a Rússia mantém relações amistosas, levaria ao consequente enfraquecimento de sua posição na região e a um novo cercamento eurasiático por parte dos EUA e Europa. Nesse sentido, a compreensão da geopolítica mundial e de suas dinâmicas, passa pela observação das Organizações de Cooperação em Defesa como 
importantes mecanismos de colaboração entre as nações e instrumentos preciosos para os interesses de grandes potências, através dos quais devem fluir as futuras relações de tensão e de aproximação, o que também deverá ser representado por uma nova regionalização do espaço mundial, orientada para fins militares.

\section{Considerações Finais}

As principais Organizações de Cooperação em Defesa se concentram no hemisfério norte e são nucleadas por grandes potências mundiais e regionais, trazendo a luz um processo histórico derivado da disputa de poder mundial entre elas. Com a evolução tecnológica e distanciamento das capacidades de poder militar entre as nações mais e menos poderosas, a cooperação tende a se tornar a saída para divisão de custos oriundos dos projetos de defesa, aliviando as pressões sobre o conjunto de nações que estão fora do principal eixo de desenvolvimento militar do planeta.

Todas as Organizações aqui destacadas foram escolhidas por sua importância em seus respectivos continentes e suas lideranças, não perfazendo, no entanto, a totalidade de acordos existentes nessa área. Porém, compreendemos que elas deverão ser as principais norteadoras dos diálogos de cooperação em defesa em suas respectivas regiões, bem como, responsáveis por orientar a condução e resolução de potenciais conflitos, tanto internamente, como entre suas zonas de contato.

Em similaridade aos processos de integração econômicos, esses mecanismos geram a exclusão de países periféricos e permitem o acesso a equipamentos de defesa somente a um pequeno número de nações, as quais buscam sua inserção e subordinação à essas alianças militares.

A Cooperação em Defesa, mais do que nunca, deve se estabelecer como característica comum dentro do futuro processo de regionalização do espaço mundial, da mesma forma que os processos de regionalização econômicos se tornaram uma orientação para a integração das nações nos anos 1990. Dessa forma, acreditamos que as análises que utilizem a teoria dos Complexos Regionais de Segurança devem levar em consideração a formação das Organizações de Cooperação em Defesa como um elemento de aglutinação e influência dentro de suas regiões.

\section{Referências}

AMINOV, Said. 2008. Analysis: Georgia's Air Defence in the August War. disponivel em: <http://www. defenceweb.co.za/index.php?option = com content\&view=article\&id=526>. Acesso em $13 \mathrm{de}$ Dezembro de 2016.

ARIS, Stephen. The Shanghai Cooperation Organisation: 'Tackling the Three Evils'. A Regional Response to NonTraditional Security Challenges or an Anti-Western Bloc?. Europe-Asia Studies, Vol. 61, No. 3 (May, 2009), pp. 457-482. Disponível em: <http://www.jstor.org/ stable/27752254> . Acesso em 10 de Janeiro de 2017.

BAEV, P. The CSTO: Military Dimensions of the Russian Reitegration Effort. In: STARR S. F., CORNELL S. V. Putin's Grand Strategy: The Eurasian Union and Its Discontents, Central Asia-Caucasus Institute \& Silk Road Studies Program, 2014, pp. 40-48. Disponível em: <https://www.silkroadstudies.org/resources/pdf/ publications/4-1409GrandStrategy-Baev.pdf>. Acesso em 10 de Janeiro de 2017.

BAJUSZ, William D. Advanced Technology and Public Policy: Multinational Weapons Acquisition. Policy Sciences, Vol. 11, No. 3, Technology and Public Policy: The Institutional Agenda (Feb., 1980), pp. 263-284. Disponível em: <http://www.jstor.org/stable/4531790>. Acesso em 27 de Janeiro de 2017.

BRZEZINSKI, Zbigniew. An Agenda for NATO: Toward a Global Security Web. Foreign Affairs, Vol. 88, No. 5 (September/October 2009), pp. 2-20. Disponível em: <http://www.jstor.org/stable/20699640>. Acesso em 17 de Janeiro de 2017.

BUZAN, Barry; WÆVER, Ole. Regions and Powers: The Structure of International Security. Cambridge, UK: Cambridge University Press, 2003.

DUARTE, Paulo de Queiroz. O Conflito das Malvinas. Rio de Janeiro, Biblioteca do Exército, 1986. Vol. 2.

FROST, Alexander. The Collective Security Treaty Organization, the Shanghai Cooperation Organization, and Russia's Strategic Goals in Central Asia. China and Eurasia Forum Quarterly, Volume 7, No. 3 (2009) pp. 83-102.

FUCILLE, Alexandre; REZENDE, Lucas P. Complexo Regional de Segurança da América do Sul: Uma Nova Perspectiva. Contexto Internacional. Rio de Janeiro, vol. 35, no 1, janeiro/junho 2013, p. 77-104.

GADDIS, John Lewis. Strategies of Cointainment. Oxford University Press, Nova Iorque, 2005. 
GOMES, P. C. C. O Conceito de Região e sua discussão. In: CASTRO, I. E; GOMES, P. C. C.; CORRÊA, R. L. (Org.). Geografia: Conceitos e Temas. 15. ed. Rio de Janeiro, Bertrand Brasil, 2012.

KEOHANE, Robert O.; NYE, Joseph S. Power and Interdependence. 4. ed. Pearson, 2012.

KISSINGER, Henry A. Política Externa Americana. Rio de Janeiro, Expressão e Cultura, 1969.

MARTINS FILHO, João Roberto. As Políticas Militares dos EUA para a América Latina (1947-1989). Teoria \& Pesquisa, N. 46. V.1, p. 105-139, 2005.

MEARSHEIMER, J. J. 2001. The tragedy of great power politics. Disponível em: <https://samuelbhfauredotcom. files.wordpress.com/2015/10/s2-mearsheimer-2001. pdf >. Acesso em 03 de fevereiro de 2017.

MEDEIRO FILHO, Oscar. Geografia Política sul-americana e percepções das agências de defesa. In: D Araújo, Maria Celina Soares; Soares, Samuel Alves; Svartman, Eduardo. (Org.). Defesa, Segurança Internacional e Forças Armadas II Encontro da ABED. Campinas, Mercado das Letras, 2009.

MONIZ BANDEIRA. Luiz A. A Desorden Mundial: O espectro da total dominação: Guerras por procuração, terror, caos e catástrofes humanitárias. Rio de Janeiro, Civilização Brasileira, 2016.

PAIVA, Luiz Eduardo Rocha. Principais Áreas de Fricção no Mundo Atual: Reflexos para a Defesa Nacional. In: ACIOLY, L; MORAES, R. F. Prospectiva, Estratégias e Cenários Globais: Visões de Atlântico Sul, África Lusófona, América do Sul e Amazônia. Brasília, IPEA, 2011.

PROENÇA Jr., Domício; DINIZ, Eugenio. Política de Defesa no Brasil: uma análise crítica. Brasília, Editora Universidade de Brasil, 1998.
PUGH, Michael C. The ANZUS Crises, Nuclear Visiting And Deterrence. Nova York, Cambridge University Press, 1989.

REZENDE, Lucas P. Sobe e desce!: Explicando a cooperação em defesa na América do Sul. Brasília, Universidade de Brasília, 2015.

SIPRI. Stockholm International Peace Research Institute. Arms Transfers Database. 2016. Disponível em: <http:// armstrade.sipri.org/armstrade/page/trade_register. php>. Acesso em 12 de Abril de 2016.

SPYKMAN, Nicholas J. America's Strategy in World Politics. New Brunswick, Transaction Publishers, 2008.

THIES, Wallace J. Why NATO Endures. Nova York, Cambridge University Press, 2009.

TURNER, Susan. RUSSIA, CHINA AND A MULTIPOLAR WORLD ORDER: THE DANGER IN THE UNDEFINED. Asian Perspective, Vol. 33, No. 1 (2009), pp. 159184. Disponível em: <http://www.jstor.org/ stable/42704667>. Acesso em 17 de Janeiro de 2017.

TEIXEIRA, Vinicius M. 2016. Os EUA e a Modernização das Forças Aéreas Sul-Americanas nos anos 1960. Anais IX Encontro Nacional da Associação Brasileira de Estudos de Defesa. Florianópolis, UFSC, 2016> Disponível em: <http://www.enabed2016.abedef.org/resources/ anais/3/1465951734_ARQUIVO_OsEUAearecomposi caodasForcasAereasSul-americanasnosanos1960.pdf>. Acesso em 12 de Dezembro de 2016

WU, Junfel. Will SCO Become Another Warsaw Pact?. Economic and Political Weekly, Vol. 40, No. 39 (Sep. 2430, 2005), pp. 4205-4207. Disponível em:<http://www. jstor.org/stable/4417189>. Acesso em 10 de Janeiro de 2017.

\section{Vinícius Modolo Teixeira}

Graduado em Licenciatura e Bacharelado em Geografia pela Universidade Federal de Uberlândia (UFU), possui mestrado pela mesma instituição. Atualmente é docente de Geografia Humana da Universidade do Estado do Mato Grosso (UNEMAT) - Campus Universitário de Sinop e Doutorando do Programa de Pós-Graduação em Geografia da Universidade Estadual de Campinas (UNICAMP). Tem atuado principalmente nos seguintes temas: Geopolítica, Conflitos e Cooperação na América do Sul e Cooperação em Defesa.

E-mail: falecomovinas@gmail.com 